\title{
ETNOMATEMÁTICA: UMA ABORDAGEM SOCIOCULTURAL NA CONSTITUIÇÃO DA APRENDIZAGEM SIGNIFICATIVA ${ }^{1}$
}

\author{
Willyan Ramon de Souza Pacheco, Universidade Federal de Campina Grande (UFCG), \\ willyanpacheco@hotmail.com \\ José Emidio da Silva Neto, Universidade Federal do Cariri (UFCA), \\ jose.emidio.12@gmail.com
}

\begin{abstract}
RESUMO
O presente artigo tem por objetivo dar enfoque etnomatemático à aquisição do conhecimento matemático que se manifesta nos mais simples e variados espaços de convivência, tendo por base o conhecimento empírico e popular que o educando traz consigo e os desafios encontrados por este ao se encontrar com o ambiente escolar. Nessa perspectiva, faremos uma breve análise histórica e etimológica que enraizaram a etnomatemática. Partindo dos estudos de Ubiratan D'Ambrosio e apoiando-se nas concepções do seu Programa Etnomatemática, visamos solucionar, ao longo desse trabalho, questões que envolvem as deficiências no processo de ensino-aprendizagem da matemática, como também, explorar quais fatores possibilitam a sua produção. Dessa forma, ao promover essa reflexividade crítica acerca do posicionamento docente, evidenciamos a imprescindivel necessidade de o professor reconhecer e valorizar as especificidades do aluno e trabalhar de forma inclusiva no âmbito de sua metodologia. É, portanto, a etnomatemática os valores históricos culturais constituídos socialmente através das relações sociais do indivíduo com a sociedade não escolarizada. Diante disso, elucidamos no professor a relevância de enxergar o discente como sujeito produtor de conhecimento, constituído de experiências, de relações, da autêntica matemática desenvolvida com o objetivo de sobrevivência e transcendência.
\end{abstract}

PALAVRAS-CHAVE: Etnomatemática; Sociedade; Aprendizagem.

\section{ETHNOMATHEMATICS: SOCIOCULTURAL APPROACH IN SIGNIFICANT LEARNING CONSTITUTION}

\begin{abstract}
This article aims to highlight the ethnomathematic for mathematic knowledge acquisition that appears in different spaces of coexistence. Starting from the studies of Ubiratan D'Ambrosio about ethnomathematic, we aim solve questions that involves the inadequacies in the process of teaching-learning of the mathematics. On this, the teacher will start to reflect on own practice and will adapt his methodology the student's specificities.

\footnotetext{
${ }^{1}$ O presente trabalho (não) contou com apoio financeiro de nenhuma natureza para sua realização.
} 
Key words: Ethnomathematic; Society; Learning.

\section{ETNOMATEMÁTICA: UN ENFOQUE SOCIOCULTURAL EN LA CONSTITUCIÓN DEL APRENDIZAJE SIGNIFICATIVO}

\section{RESUMEN}

El presente artículo tiene por objetivo dar enfoque etnomatemático a la adquisición del conocimiento matemático que se manifiesta en los más variados espacios de convivencia. A partir de los estudios de Ubiratan D'Ambrosio sobre etnomatemática, pretendemos solucionar, cuestiones que involucran las deficiencias en el proceso de enseñanzaaprendizaje de las matemáticas. El profesor pasará a reflexionar sobre su práctica y adaptará su metodología a las especificidades del alumno.

PALABRAS-CLAVE: Etnomatemática; Sociedad; Aprendizaje.

\section{INTRODUÇÃO}

O presente artigo irá explorar a Matemática em um contexto sociocultural, sem conotação sistemática, numa perspectiva construtivista. É a chamada etnomatemática, os conhecimentos empíricos construídos pela sociedade não escolarizada. É nesse contexto que buscaremos analisar como a Matemática do cotidiano pode contribuir para a aprendizagem significativa da Matemática acadêmica.

Inicialmente, partiremos de pressupostos históricos acerca da criação do Programa Etnomatemática, idealizado por Ubiratan D’Ambrosio, apresentando as situações que incitaram a sua criação. Logo mais, buscaremos de forma ampla, explorar o contexto social dos sujeitos que estão inseridos nessa abordagem: como são vistos, qual sua contribuição e de que forma o professor os recebe na escola.

A partir disso, levantaremos questões que evidenciem as principais dificuldades dos docentes e dos discentes acerca do aprendizado da matemática escolar, bem como a compreensão das relações socioculturais que contribuem para a quebra de preconceitos sobre o conhecimento prévio que o discente traz consigo. Permitindo-nos assim, enxergar uma nova maneira de ver e construir a matemática dedutiva, axiomática e formal. Tomando por base, a linguagem coloquial, os métodos baseados na intuição, na experiência e na memória histórica. 


\section{HISTORICIDADE}

No Brasil, a etnomatemática surgiu na década de 70, com fortes traços marcados pela crítica social sobre a forma tradicional de como a matemática é abordada no contexto social e educacional. O principal idealizador da etnomatemática no Brasil foi Ubiratan D’Ambrosio, que defendia a ideia de que o processo de ensino-aprendizagem deve ser norteado pelo conhecimento prévio, construído culturalmente através das relações sociais estabelecidas por cada indivíduo.

Dessa forma, surge nessa perspectiva à necessidade de compreender o sujeito em suas especificidades, a maneira de como o mesmo dispõe de um conhecimento não formal para solucionar situações cotidianas que envolvem um raciocínio matemático e o direcionam à prática espontânea dessa ação. Nesse sentido, tem-se que o conhecimento matemático é dinâmico, sendo resultado da ação humana, de sua necessidade intrínseca de sobrevivência e adaptação em uma sociedade institucionalizada. Em relação a essa ação geradora, D’Ambrosio (2005) assevera:

A ação gera conhecimento, isto é, a capacidade de explicar, de lidar, de manejar, de entender a realidade, gera o mátema. Essa capacidade se transmite e se acumula horizontalmente, no convívio com outros, contemporâneos, através de comunicações; e verticalmente, de cada indivíduo para si mesmo (memória) e de cada geração para as próximas gerações (memória histórica) (D’AMBRÓSIO, 2005, p. 110).

Assim, esse conhecimento construído coletivamente torna-se ferramenta imprescindível para a compreensão, produção e transmissão dos valores socioculturais, acumulados ao longo do processo histórico vivenciado por cada sociedade. A partir disso, a matemática é constituída como linguagem própria adaptada a realidade de cada comunidade, permitindo que seus sujeitos possam desenvolver técnicas que visam estabelecer padrões matemáticos locais, construídos cotidianamente, como: unidades de medidas, estimativas de lucro e prejuízo, noções de espaço e volume, além de porcentagem e raciocínio lógico.

Portanto, é a partir desse dinamismo cultural que torna-se possível a aquisição de uma matemática popular, construída através de saberes empíricos difundidos no âmago de uma sociedade não escolarizada.

A etnomatemática surge da inquietação de compreender que aspectos influenciadores possibilitam a produção de um conhecimento informal, de técnicas adaptadas a realidade social do sujeito que não teve contato direto com os jargões matemáticos, com o saber 
sistematizado. Sob esses aspectos, D’Ambrosio (2005) descreve como o Programa Etnomatematica se estabeleceu:

A idéia do Programa Etnomatemática surgiu da análise de práticas matemáticas em diversos ambientes culturais e foi ampliada para analisar diversas formas de conhecimento, não apenas as teorias e práticas matemáticas. E é um estudo da evolução cultural da humanidade no seu sentido amplo, a partir da dinâmica cultural que se nota nas manifestações matemáticas (D’AMBROSIO, 2005, p. 102).

Sendo assim, a etnomatemática não se limita a compreender a produção do conhecimento individual, mas busca analisar sistematicamente a sua construção coletiva, desenvolvida através das relações dialógicas entre indivíduo e sociedade. Buscando dessa forma, compreender os fatores determinantes que influenciam em sua prática, direcionando o sujeito à produção significativa do conhecimento, transformando, a partir disso, sua realidade social através da ressignificação da matemática axiomática.

A palavra etnomatemática foi criada por D'Ambrósio a partir da adaptação de três radicais gregos: etno, matema e tica. O radical etno refere-se à cultura, povo; matema está relacionada ao ato de compreender, modo de fazer; e o termo tica significa técnica. Dessa forma, compreende-se por etnomatemática a relação estabelecida por diferentes culturas ao modo de conceber a matemática como ferramenta indissociável na solução de problemas do cotidiano, estando estes relacionados ao contexto sociocultural em que se insere cada povo. Assim, D’Ambrosio e Rosa (2016) acrescentam:

A etnomatemática pode ser definida como a matemática praticada pelos membros de grupos culturais distintos, que podem ser identificados como sociedades indígenas, associação de trabalhadores, classes profissionais e grupos de crianças de uma determinada faixa etária (D’AMBROSIO; ROSA, 2016, p. 17).

Neste contexto, a etnomatematica é vista como uma ferramenta capaz de reestabelecer a dignidade humana. O sujeito passa a ser visto como produtor de conhecimento, a influência dessa aceitação é refletida em todos os parâmetros sociais, pois, agora não estamos falando daquele que não sabe ou que não domina, mas sim daquele que sabe de uma forma diferente. Reconhecer esse conhecimento popular e valorizá-lo em espaços institucionalizados, como a escola, é abrir-se as possibilidades, é olhar o sujeito e compreender sua essência para que assim, possa redirecionar a prática pedagógica numa perspectiva inclusiva.

A partir disso, podemos elucidar que o objetivo da etnomatemática não é, de forma alguma, desvalorizar ou desqualificar a matemática acadêmica, mas sim criar possibilidades 
para a interlocução de uma sobre a outra, numa articulação que favoreça a melhor compreensão e decodificação dos jargões matemáticos pelo sujeito. Criando assim, uma ação pedagógica que disponha de uma base cultural e um enfoque cognitivo para o currículo matemático, conscientizando o docente dessa harmoniosa relação. Ainda sobre a utilidade, D’Ambrosio (2001) ressalta:

De um ponto de vista utilitário, que não deixa de ser muito importante como uma das metas da escola, é um grande equívoco pensar que a etnomatemática pode substituir uma boa matemática acadêmica, que é essencial para um indivíduo ser atuante no mundo moderno. (D’AMBROSIO, 2001, p. 43)

Dessa forma, a etnomatemática busca, através da contextualização dos conhecimentos empíricos, dar significado a matemática padrão, relacionando o que eu sei com o que eu preciso saber. Ainda sobre isso Cabrera (2004) acrescenta:

A proposta da etnomatematica é fazer da matemática algo vivo, lidando com situações reais no tempo e no espaço, questionando o aqui e o agora. Assim, mergulhamos nas raízes e praticamos dinâmica cultural, reconhecendo na educação a importância das várias culturas e tradições na formação de uma nova civilização, transcultural e transdisciplinar. (CABRERA, 2004, p. 24)

Portanto, a etnomatemática se faz necessária para que possamos compreender e respeitar as variáveis culturais de cada povo, atribuindo valor humanístico à matemática e possibilitando ao docente uma visão mais ampla e contextualizada do sujeito e da região ao qual este está inserido. Com isso, passamos a ver não só a manifestação do conhecimento popular, mas também os fatores que determinam a sua construção, as relações sociais que historicamente vêm construindo significado para termos específicos e sistemáticos. Compreendendo assim, dessa forma, as pluralidades de cada indivíduo como principal característica a ser levada em consideração no contexto educacional.

\section{ETNOMATEMÁTICA E APRENDIZAGEM SIGNIFIVATIVA}

A educação, desde os primórdios de sua institucionalização, esteve compromissada veemente com o conhecimento sistematizado, com as normas e o currículo fechado para as contribuições externas dos sujeitos discentes. Dessa forma, na grande maioria das vezes a contribuição daquele que está submetido a esse sistema de ensino ditador e hierárquico, é mínima. 
Aquele que se insere nesses espaços institucionais de Ensino é conduzido obrigatoriamente a descaracterização de seus conhecimentos socioculturais, constituídos coletivamente através de suas interações humanas, da necessidade de sobrevivência, da assustadora globalização que induz essas pessoas a se adaptarem e manterem relações com a sociedade padronizada. $\mathrm{O}$ aluno que advém principalmente das classes menos favorecidas, das favelas, dos bairros periféricos, das camadas estigmatizadas da sociedade são os que, na maioria das vezes, trazem consigo a etnomatemática.

No entanto, quando este sujeito é submetido ao sistema de Ensino excludente que seleciona o que é e o que não é conhecimento, encontra-se com o abstrato, tudo o que ele sabe perdeu-se o sentido, o significado, a relevância. É nessa condição que Silva (1999) adverte:

Que tipo de percepção o aluno tem da escola e dos seus professores? Fechada no seu mundo de silêncio ou aprisionada na ideologia do cala-aboca, nem sempre a voz do aluno se faz ouvir. Discente tem que seguir as normas de boa conduta: chegar na hora, ouvir em silêncio, copiar e não perguntar, fazer as lições de casa e ir bem nas provas. (SILVA, 1999, p. 32)

Percebemos assim, a partir dessa crítica, o quanto o que o aluno traz de casa para a escola é desvalorizado. Saber só é poder quando se sabe aquilo que está escrito e legitimado. Com isso, o professor deve desenvolver conceitos básicos e contextualizados, para que assim o conhecimento se torne significativo através de metodologias que aproximem os conteúdos com a realidade social do educando, não se preocupando em nomeá-los inicialmente, mas desenvolvê-los e aprimorá-los. Em relação a isso Vitti (1999) assevera:

Trabalhando com conceitos, mesmo sem nomeá-los, a criança vai adquirindo uma habilidade matemática que só mais tarde deverá ser formalizada, ou seja, respeitar, trabalhar e desenvolver a etnomatemática, "a arte ou técnica de explicar, de conhecer, de entender nos diversos contextos culturais". (VITTI, 1999, p. 29)

Portanto, é imprescindível que haja esse respeito ao o que o educando traz consigo. A sua realidade, sua história e sua cultura estão relacionadas com seus conhecimentos. Trabalhar com seu contexto social é a melhor maneira de tornar, o que eu preciso ensinar e o que ele necessita aprender, em uma ação significativa e rica.

Nesse caso, nos falta essa associação fundamental, de colocar em prática os conhecimentos construídos socialmente. E quando isso torna-se impossível, na visão do professor, desenvolver de forma alternativa os métodos sistematizados, a frustação acontece, a decepção surge para o aluno que não consegue relacionar o conteúdo em seu contexto e do 
professor em sentir-se incapaz de construir significado na metodologia para que seus alunos apreendam.

Atribuindo, dessa forma, o fracasso escolar ao aluno, isentando o professor dessa responsabilidade de ressignificar sua metodologia para corresponder as particularidades do discente. Tudo isso porque, como mostra Vitti (1999):

Os professores, na maioria dos casos, se preocupam mais em cumprir um determinado programa de ensino do que em levantar as idéias prévias dos alunos sobre determinado assunto, pois julgam ser muito mais fácil trabalhar com uma série de exercícios padronizados do que estimular comportamentos e atitudes dos alunos, que passam por etapas evolutivas, caracterizadas por estruturas lógico-matemáticas cada vez mais elaboradas. (VITTI, 1999, p. 32)

Nessa perspectiva, o ensino da matemática deve ser impreterivelmente pensado com o aluno e não para o aluno, valorizando, considerando e trabalhando as habilidades que eles já trazem consigo. Não é o que eu sei e o que eu quero que ele saiba, mas sim, o que ele já sabe e o que ele pode relacionar com aquilo que ele não sabe, mas saberá. $\mathrm{O}$ conhecimento sistematizado deve ser constituído, deve ser mediado pelo professor, mas numa perspectiva construtivista, colaborativa e não impositiva.

Diante disso, podemos pensar no redirecionamento dessa metodologia, agora pensada com o sujeito, na ressignificação da prática docente, visando sempre a construção significativa do conhecimento metódico. Assim, Freire (2001) assevera:

Pensar certo coloca ao professor ou, mais amplamente, à escola, o dever de não só respeitar os saberes com que os educandos, sobretudo os das classes populares, chegam a ela - saberes socialmente construídos na prática comunitária -, mas também [...] discutir com os alunos a razão de ser de alguns desses saberes em relação com o ensino dos conteúdos. (FREIRE, 2001, p. 31)

Dessa forma, compreendemos que a responsabilidade de elucidar a relevância desses conhecimentos construídos nas relações socioculturais, não está apenas no professor, mas sim no movimento de toda a escola em valorizar e dar significado as experiências que o educando traz consigo. Ainda sobre o redirecionamento dessas metodologias, Vitti (1999) acrescenta:

Se o ensino e o desenvolvimento da matemática fosse inspirado nas necessidades e realidade do homem e em seu momento histórico, e não apenas levando aos alunos regras e mais regras, dizendo que isso é matemática, além de estarmos contemplando um binômio indissociável em didática - o que vou ensinar e para que vou ensinar -, também amenizaria a 
violência que é praticada contra a criatividade do aluno moderno, tentando ensinar matemática à moda tradicional. (VITTI, 1999, p. 40)

E aqui nos encontramos com o fator responsável pela falta de interesse pela matemática. O professor que não desenvolve métodos que estimulem a criatividade do aluno em buscar saber onde tais técnicas podem ser inseridas no seu cotidiano, está subjetivamente fazendo com que estes aprendam por indução e não pela consciência de necessidade e relevância. É imprescindível que o educando saiba onde surgiu tais cálculos, por quem e o porquê de está aprendendo aquilo, para que irá servir e qual a relevância para sua formação.

Assim, o professor deve estar preparado para esses questionamentos, e mesmo quando estes não aparecerem, é necessário que exista essa contextualização para que assim possa surgir o processo de assimilação subjetiva e consequentemente a construção da aprendizagem significativa do conteúdo.

Além disso, é no processo de ensino aprendizagem, que deve ser direcionado ao professor a elucidação da importância de interação com o aluno, para que ambos possam no âmbito dos múltiplos espaços de aprendizagem, pensar a melhor maneira de construir significado no Ensino da matemática. Transformando essa ação desinteressante, cansativa e até traumatizante, numa prática transformadora, em uma ferramenta capaz de motivar o aluno e direcioná-lo novamente ao campo das possibilidades, da interação e da criatividade.

Fazendo assim, o professor ser estimulado a prosseguir em sua profissão com um novo posicionamento, numa nova perspectiva, sendo sob a ótica do construtivismo, um profissional crítico e reflexivo. Dessa forma, Vitti (1999) acrescenta:

O ensino aprendizagem da matemática pode e deve ser encarado de uma maneira prazerosa, tanto para professores como para alunos. Se o ensino da matemática fosse fundamentado na concepção da matemática como conhecimento historicamente construído e que se reconstrói a cada instante, despertaria mais a atenção e o interesse dos alunos, suscitando prazer naquilo que está aprendendo. A união entre ensino, paixão e prazer estaria assegurada. (VITTI, 1999, p. 96)

Portanto, que os professores possam mostrar a matemática em todos os seus espaços, criando um elo de aproximação entre o discente e o mundo, minimizando os equívocos, desmistificando os mitos e otimizando o prazer matemático que nasce através do esclarecimento, do discernimento, da significação dos conceitos abstratos. Para que só assim, a constituição da aprendizagem significativa, construída coletivamente nos múltiplos espaços 
de aprender, seja efetivamente prática conduzida pelo docente e direcionada ao aluno intencionalmente.

\section{CONSIDERAÇÕES PROVISÓRIAS}

Levando-se em conta o que foi observado, faz-se necessário deixarmos evidente a importância de nos inserirmos no âmbito sociocultural do sujeito, construindo a partir do esclarecimento uma postura docente crítica-reflexiva, onde o discente agora é qualificado como sujeito que produz, que traz consigo experiências favoráveis a aquisição do conhecimento matemático axiomático. Aqui não finalizamos esse estudo, ainda há muito para explorar no campo etnomatemático, precisamos não só compreender a importância, mas a necessidade da prática, da ação humanística de reconhecer o conhecimento do sujeito que fala légua ao invés de quilômetro.

Dessa forma, a etnomatemática busca assimilar no ensino da matemática todos os espaços socioculturais ao qual o sujeito está inserido, valorizando sua historicidade e construindo a partir dessa compreensão, significado em torno do processo de ensinoaprendizagem, desmistificando o mito da matemática difícil e compreendendo o sujeito em sua singularidade.

\section{REFERÊNCIAS BIBLIOGRÁFICAS}

CABRERA, Silvia Regina Trento. A etnomatemática: teoria e prática. 2004.57 f. Monografia (Especialização) - Curso de Educação Matemática, Universidade do Extremo Sul Catarinense, UNESC, Criciúma, 2004.

D’AMBROSIO, Ubiratan. Etnomatemática: elo entre as tradições e a modernidade. Belo Horizonte: Autêntica, 2001.

D'AMBROSIO, Ubiratan. Sociedade, cultura, matemática e seu ensino. Educação $e$ Pesquisa, São Paulo, v. 31, n. 1, p. 99-120, jan./abr. 2005.

D’AMBROSIO, Ubiratan.; ROSA, Milton. Um diálogo com Ubiratan D’Ambrosio: uma conversa brasileira sobre etnomatemática. In: BANDEIRA, Francisco de Assis.; GONÇALVES, Paulo Gonçalo Farias. (Orgs.). Etnomatemáticas pelo Brasil: aspectos teóricos, ticas de matema e práticas escolares. Curitiba: CRV, 2016. p. 13-38. 
FREIRE, Paulo. Pedagogia da autonomia: saberes necessários à prática educativa. 43. ed. São Paulo: Paz e Terra, 2011.

SILVA, Ezequiel Theodoro da. Magistério e mediocridade. $4^{\circ}$ ed. São Paulo: Cortez, 1999.

VITTI, Catarina Maria. Matemática com prazer: a partir da história e da geometria. $2^{\circ}$ ed. Piracicaba: Unimep, 1999. 